\title{
Asian Motility Studies in Irritable Bowel Syndrome
}

\author{
Oh Young Lee, MD
}

Division of Gastroenterology, Department of Internal Medicine, Hanyang University Medical Center, Seoul, Korea

\begin{abstract}
Altered motility remains one of the important pathophysiologic factors in patients with irritable bowel syndrome (IBS) who commonly complain of abdominal pain and stool changes such as diarrhea and constipation. The prevalence of IBS has increased among Asian populations these days. Gastrointestinal (GI) physiology may vary between Asian and Western populations because of differences in diets, socio-cultural backgrounds, and genetic factors. The characteristics and differences of GI dysmotility in Asian IBS patients were reviewed. MEDLINE search work was performed including following terms, 'BBS,' 'motility,' 'transit time,' 'esophageal motility, ' 'gastric motility,' 'small intestinal motility,' 'colonic motility,' 'anorectal function,' and 'gallbladder motility' and over 100 articles were categorized under 'esophagus,' 'stomach,' 'small intestine,' 'colon,' 'anorectum,' 'gallbladder,' 'transit,' 'motor pattern,' and 'effect of stressors.' Delayed gastric emptying, slow tansit in constipation predominant IBS patients, rapid transit in diarrhea predominant IBS patients, accelerated motility responses to various stressors such as meals, mental stress, or corticotrophin releasing hormones, and altered rectal compliance and altered rectal accomodation were reported in many Asian studies regarding IBS. Many conflicting results were found among these studies and there are still controversies to conclude these as unique features of Asian IBS patients. Multinational and multicenter studies are needed to be performed vigorously in order to elaborate characteristics as well as differences of altered motililty in Asian patients with IBS.
\end{abstract}

(J Neurogastroenterol Motil 2010;16:120-130)

Key Words

Irritable bowel syndrome, Gastrointestinal motility, Asia

\section{Introduction}

Irritable bowel syndrome (IBS) is defined as a chronic and recurrent disorder characterized by abdominal pain or discomfort and altered bowel habits in the absence of any detectable structural abnormality. The main pathophysiologic factors of IBS are altered visceral perception and motility. ${ }^{1-8}$ IBS has also been called 'spastic colon,' implying a motility disorder. Some IBS patients may show altered motor patterns or transit depending on changes in stool patterns. Altered motility from abnormal gut contractions may result in IBS symptoms such as abdominal pain and discomfort. Many studies have shown that IBS patients have various gastrointestinal (GI) motor disturbances that often arise from an exaggerated physiological response to stimuli such as diet and stress. ${ }^{9-12}$

Received: January 29th, 2010 Accepted: March 23rd, 2010

(c) This is an Open Access article distributed under the terms of the Creative Commons Attribution Non-Commercial License (http://creativecommons. org/licenses/by-nc/3.0) which permits unrestricted non-commercial use, distribution, and reproduction in any medium, provided the original work is properly cited.

*Correspondence: Oh Young Lee, MD

Division of Gastroenterology, Department of Internal Medicine, Hanyang University Medical Center, 17 Haengdang-dong, Seongdong-gu, Seoul 133-792, Korea

Tel: +82-2-2290-8343, Fax: +82-2-2298-9183, E-mail: leeoy@hanyang.ac.kr

Financial support: None.

Conflicts of interest: None. 
Altered bowel transit could account for IBS symptoms including changes in bowel habit. IBS patients with diarrhea tend to have accelerated intestinal transit while those with constipation usually have delayed intestinal transit, although a few studies failed to demonstrate this association. ${ }^{13,14}$

Altered motilities have been reported in the entire GI tract of IBS patients. However, abnormal motor activities may be primary or secondary, ${ }^{15,16}$ and there are no consistent abnormal motor patterns of IBS patients, making it difficult to interpret the significance of these findings. Some abnormal motor patterns are neither specific nor diagnostic for IBS.

Regardless of the pathogenesis of IBS, antispasmodics are used to control the abdominal pain and discomfort, and promotility drugs to control abnormal GI transit and related symptoms. Therapeutic benefits of antispasmodic drugs were reported on diarrhea predominant IBS patients in a study from Taiwan ${ }^{17}$ indicating that control of abnormal motility is important for treatment of some IBS symptoms.

Table 1. Asian Motility Studies in Irritable Bowel Syndrome

\begin{tabular}{|c|c|c|c|}
\hline Organs & $\begin{array}{c}\text { Motility } \\
\text { parameters }\end{array}$ & Results & References \\
\hline \multirow[t]{2}{*}{ Stomach } & GET & Delayed compared to controls & Seo et $\mathrm{al}^{41}$ \\
\hline & EGG & Not different from controls & Seo et al. ${ }^{41}$ \\
\hline \multirow[t]{5}{*}{ Small intestine } & HBT & Delayed transit in IBS-C, accelerated transit in IBS-D & Lu. et al. ${ }^{44}$ \\
\hline & MMC & $\begin{array}{l}\text { Decreased amplitude and velocities of phase III in IBS-C, } \\
\text { Increased amplitude and velocities of phase III in IBS-D, } \\
\text { No association between DCC and pain }\end{array}$ & Wang et al. ${ }^{53}$ \\
\hline & & Shortened duration of MMC cycle, prolonged phase III duration & Zhao et al. ${ }^{56}$ \\
\hline & Effect of stressors & Duodenal dysmotility to $\mathrm{CRH}$ & Fukudo et al. ${ }^{59}$ \\
\hline & & Blunted duodenal response to balloon distension of colon & Fukudo et al. ${ }^{103}$ \\
\hline \multirow[t]{12}{*}{ Colon } & CTT & Delayed in IBS-C, not different from controls in IBS-D & Lu et al. ${ }^{14}$ \\
\hline & & Not characteristic in IBS compared to $\mathrm{HC}$ & Horikawa et al. ${ }^{64}$ \\
\hline & & Delayed in IBS-C, accelerated in IBS-D & $\begin{array}{l}\text { Koo et al. } .^{74} \\
\text { Nar et al. }\end{array}$ \\
\hline & & Stool forms correlate with CTT, CTT correlates with abdominal pain & Chiba et al. $^{78}$ \\
\hline & Effect of stressors & Increased motility during mental stress & Fukudo et al. ${ }^{95}$ \\
\hline & & Greater increase with $\mathrm{CRH}$ compared to controls & Fukudo et al. ${ }^{59}$ \\
\hline & & Increased MI to balloon distension compared to controls & Fukudo et al. ${ }^{103}$ \\
\hline & & $\begin{array}{l}\text { CRH increases colon motility, blockage of } \mathrm{CRH} \text { receptor } \\
\text { inhibits the increased motility }\end{array}$ & Sagami et al. ${ }^{100}$ \\
\hline & $\begin{array}{l}\text { Postprandial } \\
\text { colonic motility }\end{array}$ & $\begin{array}{l}\text { Larger change in frequency of propulsion in IBS-C, smaller change } \\
\text { in frequency of contractions in IBS-C compared to HC }\end{array}$ & Kusunoki et al. ${ }^{104}$ \\
\hline & & $\begin{array}{l}\text { Postprandial colonic transit after spicy meals and meals with chili } \\
\text { capsules did not differ from standard meals in IBS-D and controls }\end{array}$ & Gonlachanvit et al. ${ }^{107}$ \\
\hline & & No dysmotility after high chili diet & $\begin{array}{l}\text { Agarwal et al. } \\
\text { Shah et al. }\end{array}$ \\
\hline & & $\begin{array}{l}\text { MI of sigmoid colon in IBS-D higher than IBS-C and HC, } \\
\text { MI of descending colon in IBS-C higher than IBS-D and HC }\end{array}$ & Jeong et al. ${ }^{105}$ \\
\hline \multirow[t]{3}{*}{ Anus \& Rectum } & Compliance & $\begin{array}{l}\text { Decreased rectal compliance in IBS-D after meal, no differences of } \\
\text { rectal compliance during fasting between IBS-C and IBS-D }\end{array}$ & Lee et al. ${ }^{114}$ \\
\hline & & $\begin{array}{l}\text { Difference in static compliance between IBS and controls, } \\
\text { no difference in dynamic compliance }\end{array}$ & Park et al. ${ }^{110}$ \\
\hline & $\begin{array}{l}\text { Rectal } \\
\text { accommodation }\end{array}$ & Lower in IBS-D compared with HC & Moon et al. ${ }^{115}$ \\
\hline Gallbladder & $\begin{array}{l}\text { Motility after } \\
\text { caerulein injection }\end{array}$ & Hyperkinetic in IBS-C, hypokinetic in IBS-D & Kanazawa et al. ${ }^{116}$ \\
\hline
\end{tabular}

GET, gastric emptying time; EGG, electrogastrography; HBT, hydrogen breath test; MMC, migrating motor complex; CTT, colon transit time; IBS, irritable bowel syndrome; IBS-C, constipation predominant IBS; IBS-D, diarrhea predominant IBS; DCC, discrete clustered contraction; CRH, corticotropin-releasing hormone; HC, healthy control; MI, motility index. 
Nowadays, the pathophysiology of IBS is focused on visceral perception or brain gut interaction, but altered motility still remains to be important. Epidemiologic studies have shown that the prevalence of IBS is increasing in Asian communities, perhaps due to rapid socioeconomic development and changes in dietary patterns. Therefore, IBS is of increasing interest in Asia. The characteristics of IBS in Asia may differ from those of Western societies based on diets, socio-cultural backgrounds, and genetic factors.

Here I review the evidence for altered GI motility in IBS patients with a specific focus on Asian populations. Table 1 gives a detailed summary of Asian GI motility studies in IBS.

\section{Methods}

The literature search included MEDLINE and manual searches of bibliographies of articles published from 1987 to 2009. MEDLINE search terms included 'IBS,' 'motility,' 'transit time,' 'esophageal motility,' 'gastric motility,' 'small intestinal motility,' 'colonic motility,' 'anorectal function.' More than 100 articles and abstracts were reviewed and relevant issues categorized under 'esophagus,' 'stomach,' 'small intestine,' 'colon,' 'anorectum,' 'gallbladder,' 'transit,' 'motor pattern,' and 'effect of stressors' were identified for detailed elaboration.

\section{Esophagus}

Several Asian studies have indicated that esophageal symptoms such as heartburn or regurgitation are more prevalent in IBS patients. Overlap between IBS and gastroesophageal reflux disease is common in the general population, ${ }^{18}$ and the association between IBS and abnormal esophageal motilities were also reported in the study. ${ }^{19}$ The study showed more frequent simultaneous and repetitive contractions and impaired lower esophageal sphincter tone in IBS patients compared to healthy individuals. However, other investigators have failed to demonstrate abnormal esophageal motility in IBS. ${ }^{20,21}$ Even though esophageal symptoms are commonly found in IBS patients, the evidence supporting abnormal esophageal motor dysfunctions in IBS is not yet sufficient.

\section{Stomach}

Many IBS patients also complain of upper GI symptoms such as epigastric fullness, nausea, vomiting, and In Asians, IBS commonly overlaps with functional dyspepsia. ${ }^{19,22-26}$ In a population based study in India, the prevalence of dyspepsia was found to be higher in IBS patients compared to the general population. ${ }^{27}$ In a study from Taiwan, nearly $60 \%$ of Rome I-defined functional dyspepsia subjects and $18.9 \%$ of Rome II-defined functional dyspepsia subjects overlapped with IBS. ${ }^{28}$ IBS was found to be very often overlapped with functional dyspepsia defined by Rome III criteria and the presence of postprandial fullness symptom was known to be a risk factor for overlap. ${ }^{29}$ Patients with functional dyspepsia visiting gastroenterologists had concomitant IBS in $22 \%$ of population in a region of China, where the prevalence of IBS in this population was estimated to be only $7 \%{ }^{30}$

Stress is a well-known factor to play a major role in the development of symptoms in functional GI disorders like IBS. ${ }^{31-33}$ Stress may affect both gastric and colonic motor functions in IBS patients, which suggests that abnormal gastric motility such as delayed gastric emptying might occur in IBS patients. There are inconsistent reports regarding gastric emptying in IBS patients. Gastric emptying time was delayed more often in constipation predominant IBS patients than in diarrhea predominant IBS patients or in healthy controls. ${ }^{34,35}$ In addition, patients with concomitant dyspeptic symptoms showed delayed gastric emptying. ${ }^{36}$ However, there have been other studies failed to demonstrate abnormal gastric emptying. ${ }^{37-40}$ A Korean study reported that gastric emptying time in IBS patients was delayed compared to healthy controls while dyspeptic symptoms were not correlated with gastric emptying time. ${ }^{41}$ Their measurements using electrogastrography revealed no statistical difference between the patients with and without dyspeptic symptoms or between the IBS patients and healthy controls. Therefore, dyspeptic symptoms in IBS patients might be related to other factors such as abnormal sensory function or brain-gut interactions rather than abnormal motor function of the stomach.

There is an interesting report regarding antral motor change in response to stressor. The motor activity of the distal antrum significantly decreased during administration of anger stressor in IBS patients but increased in normal controls. ${ }^{42}$

In summary, studies of gastric motility in IBS show that some IBS patients have abnormal gastric emptying. Constipation predominant IBS patients had delayed gastric emptying more frequently than healthy controls or diarrhea predominant IBS patients. However, the relationship between abnormal gastric motility such as abnormal gastric emptying and other dyspeptic symptoms in IBS patients is unclear. 


\section{Small Intestine}

\section{Small bowel transit}

Small bowel dysmotility is one of the manifestations of IBS. Several studies have reported that small intestinal transit was slow in constipation predominant IBS patients and rapid transit in diarrhea predominant IBS patients. ${ }^{13,43}$ Similarly, small bowel transit measured by using non-invasive hydrogen breath tests in the fasting state demonstrated delayed transit in constipation predominant IBS and rapid transit in diarrhea predominant IBS in Taiwanese study. ${ }^{44}$ Additional findings of the study were that the bigger the body mass index, the more prolonged the small bowel transit time, and that there was a significant correlation between age and small bowel transit times regardless of the predominant bowel habit.

\section{Small bowel motor patterns}

Evaluation of small bowel motility can be invasive or require long time periods due to the diurnal variation of small intestinal motor activity and have a difficulty in performing and interpreting it. Although several small bowel motor disturbances have been reported in IBS patients, the studies of small bowel motility have yielded inconsistent results. According to duodenojejunal motor activity obtained by continuous 72 hours recordings in IBS patients, the duration of postprandial motor activity was shorter in IBS patients than in controls during the day, diurnal migrating motor complex (MMC) intervals were shorter in diarrhea-predominant IBS patients than in constipation-predominant IBS patients and there was no difference in the patterns of motor activity during sleep. ${ }^{45}$ Several studies have documented discrete clustered contractions (DCCs) in jejeunal recordings in IBS patients, ${ }^{45-47}$ although these were also documented in control subjects. ${ }^{48,49}$ In addition, DCCs have been seen in the recordings from patients with either mechanical intestinal obstruction or pseudo-obstruction. ${ }^{50-52}$ Therefore, DCCs were considered to be nonspecific motor responses to the stress of manometric procedure. $^{48}$

In a recent study from China, differences between IBS patients and healthy controls in MMC were investigated using 16-channel water-perfused manometry. The contraction amplitude and propagation velocities of phase III decreased significantly in constipation predominant IBS patients compared to healthy controls. In contrast, the same parameters increased sig- nificantly in diarrhea predominant IBS patients. The incidence of DCCs was similar in IBS patients and normal healthy controls. Abnormal phase III contractions appeared in more than half of the IBS patients, but not in healthy controls. ${ }^{53}$ The investigators suggested that pathogenesis of IBS may include small intestinal motility dysfunction. However, another study reported no increase in DCCs and normal frequencies of MMCs. ${ }^{54}$ The correlation between DCCs of small bowel and IBS symptoms such as abdominal pain have been demonstrated by several studies. ${ }^{45-47,55}$ It was reported that $46 \%$ of DCCs were accompanied by abdominal pain and that $68 \%$ of pain episodes were associated with DCCs. ${ }^{46,47}$ However, other investigators failed to find a correlation. ${ }^{53}$ Therefore, the correlation between DCCs and IBS symptoms remains to be clarified.

The relationship between interdigestive MMCs and plasma GI hormones in IBS patients has been studied in China. Compared with healthy controls, diarrhea predominant IBS patients had shortened durations of MMC cycles and prolonged phase III durations with greater amplitudes and faster prolongation velocities. Opposite outcomes were observed in constipation predominant IBS patients. The peak plasma motilin level was recorded in phase III of the MMC cycles. Plasma 5-hydroxytyptamine fluctuated periodically in phase with MMC cycles, reaching a peak level in phase II. ${ }^{56}$

\section{Effect of stressors on small bowel motility}

Several interesting studies have investigated the effects of various stressors in IBS patients. IBS patients and controls had similar durations of small bowel motor responses after meals. 49,57

In a study that investigated the motor response of the gallbladder and small bowel to cholecystokinin, relative motility index, defined as the intestinal motility index at the time of the maximal meal-induced gallbladder contraction, was exaggerated in the jejunum in IBS patients compared to controls. ${ }^{46}$

Mental stress has been known to inhibit MMCs. ${ }^{55,58}$ Mental stress caused cessation of MMCs and irregular contractile activities of upper small bowel in IBS patients. ${ }^{55}$

When corticotropin-releasing hormone $(\mathrm{CRH})$ was administered intravenously to IBS patients during duodenal manometry, duodenal motility was observed to be exaggerated by exogenous $\mathrm{CRH}^{59}$ While baseline comparisons of IBS patients and controls showed no significant differences in the patterns of duodenal motility, phase III motor activity of the duodenum was evoked significantly by CRH administration in both IBS patients and controls. However, after CRH administration, IBS patients 
had a significantly higher incidence of duodenal dysmotility as well as a longer duration of abdominal symptoms than controls.

\section{Colon}

Many studies have shown that IBS patients have various colonic motor disturbances. Altered colonic motility was thought to be related to IBS symptoms because IBS patients frequently complain of bowel habit changes. Therefore, colon is considered the most important organ among the GI tracts for the development of IBS symptoms. In fact, colon has been a focus of many investigations including motility studies.

\section{Colon transit}

\section{1) Colon transit time in IBS}

Several factors may affect colon transit time. From a recent Chinese study, high dietary fiber intake of 40-50 g per day resulted in a significantly shorter whole gut transit time compared to daily intake of $10-20 \mathrm{~g} .{ }^{60}$ This result suggests that dietary fiber may affect colon transit time. However, colon transit time could vary depending on several other factors such as methodology used, amount of fiber intake during the study and baseline characteristics. It is needed to consider these factors when conducting a study of colon transit time and interpreting the results.

Altered colon transit could contribute to changes in stool patterns and IBS symptoms. Many studies of colon transit in Asian IBS patients have suggested a general trend for the diarrhea predominant IBS patients to have accelerated colon transit and for the constipation predominant IBS patients to have delayed colon transit, in agreement with some Western studies. ${ }^{61,62}$ However, several studies failed to demonstrate differences between IBS and controls in colon transit time. ${ }^{63,64}$ One Indian study reported that there was no difference in colon transit time between IBS patients and normal healthy controls after ingestion of chillies. ${ }^{63}$ Radioopaque markers were used to measure colon transit time in men with IBS and ingestion of chillies did not increase bowel frequency in IBS patients. Another study in Japan did not report any characteristics in colon transit times in IBS patients. ${ }^{64}$

\section{2) Asian vs. Western}

Indians who don't complain of lower abdominal pain are reported to have 1-2 bowel movements per day. ${ }^{65}$ Over $60 \%$ of subjects surveyed in Thailand and Singapore, approximately $40 \%$ in Korea and $84 \%$ in China reported bowel movements once daily. ${ }^{66-69}$ Consumption of fiber or spicy foods may be higher in Asian compared to Western populations. Given such dietary dif- ferences, GI transit may also be different in Asian populations. One Indian study reported that normal stool frequency was one or more a day, and twice a day for IBS patients ${ }^{65}$ compared to a normal stool frequency between 3 per week and 3 per day in the West. Moreover, some reports mentioned that mean colon transit time was 18 hours in the north Indian population compared with 35 hours in Western populations. ${ }^{70-73}$ A study from Korea reported that colon transit time was faster in Koreans than in Westerners. ${ }^{74}$ However, in a recent study from Hong Kong, there was no significant ethnic difference in colon transit time between Chinese adults in Hong Kong and Caucasian adults in the developed world. $^{75}$

Despite the current lack of a direct comparative study of Asian and Western GI transit, several studies allow speculation that colon transit times are indeed shorter in normal Asian populations.

\section{3) Colon transit time according to IBS subtype}

According to a recent study conducted in Singapore, colon transit time was much slower in constipation predominant IBS patients compared to normal healthy controls, but not in diarrhea predominant IBS patients. ${ }^{14}$ Delayed colon transit time could thus be an important marker for constipation predominant IBS patients. ${ }^{14}$ However, no difference was reported in colon transit time between constipation predominant IBS and normal controls in Japan, with faster colon transit time in diarrhea predominant IBS patients. ${ }^{13}$ Two other Asian studies from Korea reported delayed colon transit in constipation predominant IBS and accelerated colon transit in diarrhea predominant IBS. ${ }^{74,76}$

In summary, Asian and Western studies of colon transit in IBS patients similarly showed that accelerated gut transit and delayed bowel transit occurred in diarrhea and constipation predominant IBS, respectively, although this correlation was not absolute.

\section{4) Correlation between stool forms, IBS symptoms and colon transit}

Stool forms are reported to be relevant to colon transit time with shorter transit times correlating with diarrhea and longer transit times correlating with constipation. ${ }^{77}$ However, the correlation between colon transit time and stool forms is still under debate. A study from Japan found that colon transit time was indeed correlated with stool forms or bowel movements. Stool forms themselves were highly correlated with bowel movements, and abdominal pain was also correlated with colon transit time significantly. ${ }^{78}$ However, stool forms do not always correlate with transit times or IBS subtype (constipation or diarrhea predom- 
inant).

\section{Colonic motor patterns: basal colonic motility}

Colonic motility usually decreases during sleep and rapidly increases right after awakening. After measuring pan-colonic pressure over whole digestive cycles using single telemetry capsules, both the number of pressure contractions and the area under the pressure contractions were significantly decreased during sleep. ${ }^{79}$ Also both in response to waking and meals and in circadian behavior colonic motility showed significant regional variations. Healthy subjects and IBS patients often have many same motor events. There have been many such studies that failed to demonstrate differences in colonic motility, not only between IBS patients and healthy controls, but also among IBS subgroups. ${ }^{15,16,80}$ However, there seems to be a general trend for diarrhea predominant IBS patients to have a great number of colonic contractions or high amplitude propagating contractions (HAPCs), and for the constipation predominant IBS patients to have fewer HAPCs, although all studies have not demonstrated this. HAPCs have been demonstrated to coincide with abdominal cramps by many studies. HAPCs were more common in patients exhibiting diarrhea than in normal controls and were responsible for abdominal pain. ${ }^{81}$

\section{Effect of stressors on colon motility}

Daily stressful events are more commonly reported in IBS patients than non-IBS patients and healthy controls. ${ }^{31-33,82-84}$ According to many Asian studies IBS subjects have noted higher anxiety and depression scores compared to controls. ${ }^{24,26,85-89}$ Emotional stress plays major important role in symptom development of functional GI disorders especially in IBS patients whose stress may not only initiate but exacerbate GI symptoms. ${ }^{32,83,84,90-93}$ Although such correlation between symptoms and stress are also observed in healthy subjects, the response to stress is greater and more persistent in IBS patients than healthy controls. ${ }^{94}$ Several studies of IBS have shown colonic dysmotility in response to various stressors including emotional stress, meal ingestion, $\mathrm{CRH}$ infusion, and colonic distensions using a balloon. Among them, emotional stress is a well known factor affecting colonic motility. An exaggerated colonic response to stress was reported. One Japanese study investigated the effect of artificial mental stress on colonic motility in IBS patients. ${ }^{95}$ When a transducer was inserted into the sigmoid colon from the anus along with a mirror drawing test loaded as psychological stress, colonic motility during the stress period increased significantly in IBS patients com- pared to controls.

Enhanced colonic motility was also observed in response to $\mathrm{CRH}$ that is known to be a major mediator of a stress response. IBS has been considered as a disorder of the brain-gut interaction associated with an enhanced response to stress. Stress-related activation of $\mathrm{CRH}$ receptors was shown to produce alterations of GI functions. ${ }^{96}$ Several earlier studies demonstrated that $\mathrm{CRH}$ receptor antagonists could inhibit the altered gut motility induced by stress. ${ }^{97-99}$ It was also found that exogenous $\mathrm{CRH}$ exaggerated colonic motility. ${ }^{59}$ When $\mathrm{CRH}$ was administered intravenously to IBS patients during colonic manometry, $\mathrm{CRH}$ induced motility of the descending colon in both groups with greater motility indexes in IBS patients compared to controls despite a lack of a significant correlation between the duration of abdominal pain and colonic motility index. ${ }^{59}$

When tone of the descending colon and intraluminal pressure of the sigmoid colon were measured before, during and after rectal electrical stimulation and after peripheral administration of $\alpha$-helical CRH, a non-selective $\mathrm{CRH}$ receptor antagonist, rectal electrical stimulation induced significantly higher motility indices of the colon in IBS patients compared to controls, and this enhanced colonic motility by rectal electrical stimulation was suppressed by peripheral administration of $\alpha$-helical CRH in IBS patients but not in controls. ${ }^{100}$ These results suggest that experimental stress or CRH could increase colonic motility in IBS patients and that this motility change could be blocked by the administration of $\alpha$-helical CRH. Although the mechanism whereby $\alpha$-helical CRH affects GI function is unknown, peripheral administration of $\mathrm{CRH}$ notably increases colonic motility and blockage of peripheral CRH1 receptors inhibits this increase. ${ }^{101}$ Blockage of the enteric nervous system by lidocaine inhibits activation of colonic segments induced by $\mathrm{CRH}$ in vitro. ${ }^{102}$ Taken together, the administration of $\alpha$-helical CRH clearly decreases colonic motility in IBS patients, probably by antagonizing $\mathrm{CRH} 1$ in the enteric nervous system. ${ }^{100}$

The main pathophysiologic findings of IBS are altered motility and visceral perception. However, we still do not know how visceral perception and GI motility are connected. A Japanese study investigated the connections between intestinal distension and motor response. When a manometric catheter was inserted into the descending colon and duodenum, repetitive balloon-dependent distensions of the distal sigmoid colon below the sensory threshold induced a significant increase in motility indices of the descending colon in IBS patients compared to controls. ${ }^{103}$ Duodenal motility indices were significantly reduced by colon 
distension in controls but not in IBS patients. The sensory threshold of balloon distension was significantly lower in IBS patients than in controls. Therefore, IBS patients may have not only visceral hypersensitivity but also an abnormal intestinal reflex. In summary, GI motility in IBS patients is characterized by an altered, and mainly exaggerated, response to stressors.

\section{Postprandial colonic motility}

IBS patients typically complain of symptoms after meal ingestion. Some specific foods or dietary constituents seem to cause and aggravate IBS symptoms. It appears that an exaggerated response to meal ingestion is one of the most consistent colonic dysmotilities in IBS, most commonly increased colonic motility.

In one recent study from Japan, that used ultrasonography to investigate motor function of the sigmoid colon before and after meals, changes in the frequency of segmental contractions were smaller in constipation predominant IBS patients, whereas changes in the frequency of propulsion were larger in diarrhea predominant IBS patients. ${ }^{104}$ There is another study that investigated the differences in postprandial colonic motility between IBS patients and normal healthy controls. ${ }^{105}$ They measured change of colonic motility index as a percentage change over the basal period in response to a meal. The percentage changes of the motility index after meals were higher in the sigmoid colon of diarrhea predominant IBS patients than that of constipation predominant IBS patients. The percentage changes of the motility index after meals were higher in the descending colon of the patients with abdominal pain than in that of normal controls and diarrhea predominant IBS patients or constipation predominant IBS patients. However, there were no differences between normal controls and IBS subgroups in the frequency of propagating contractions after meals.

Rectosigmoidal motility was found to be unaffected in after a high-chili diet an Indian study. ${ }^{106}$ In contrast, another study in Thailand evaluated the effect of chili-containing foods on postprandial GI symptoms and colon transit time in diarrhea predominant IBS. Spicy meals and meals with chili capsules induced only mild abdominal burning relative to standard meals in healthy volunteers, whereas they induced significant levels of abdominal pain and burning in diarrhea predominant IBS patients. Postprandial colonic transit was independent of chili-containing meals, suggesting that diarrhea predominant IBS patients exhibited gut hypersensitivity to chili. ${ }^{107}$

Although there are outliers, a general trend exists for diarrhea predominant IBS patients to have increased colon motility after meal ingestion. GI motility disturbances may arise from an exaggerated physiological response to meals in IBS patients.

\section{Anus and Rectum}

Anorectal function is important for bowel movements. IBS patients frequently complain of urgency, incomplete bowel movements or straining, implying abnormal anorectal functions in IBS. When anorectal manometry was used to investigate anorectal function in IBS patients, no differences was found in maximum basal pressure, maximum squeezing pressure, threshold of anorectal inhibitory reflex, threshold of the first sensation, and threshold of defecation between IBS patients and normal controls. However, the volume eliciting sense of defecation, urgency, and maximum tolerable discomfort was significantly lower in diarrhea predominant IBS patients than in constipation predominant IBS patients, suggesting that abnormal anorectal physiology may contribute to the development of IBS symptoms. ${ }^{108}$ Although altered rectal compliance has been reported in IBS patients, findings have been inconsistent. Volume thresholds for stool were reported lower in diarrhea predominant IBS patients compared to normal controls or constipation predominant IBS patients. ${ }^{109}$ Rectal compliance was also lower in diarrhea predominant IBS patients. Recent study from Asia evaluated rectal compliance in IBS patients by barostat. ${ }^{110}$ Significant differences in static but not dynamic compliance were found between IBS patients and normal healthy subjects. Dynamic and static compliance were not significantly different between diarrhea and constipation predominant IBS patients. ${ }^{110}$ However, these results were inconsistent to other studies showing lower dynamic compliance in diarrhea than in constipation predominant IBS patients. ${ }^{111-113}$ Inconsistent findings may be due to the differences in sample size, in definitions of IBS and subgroups, in location of the colon studied, and in methodology such as different devices used or duration of colonic distension applied.

Abnormal rectal physiology such as altered rectal function after meals may be a main contributor to the development of meal-induced IBS symptoms. A recent barostat study from Korea confirmed that meals changed rectal compliance. Rectal compliance in IBS patients was unchanged during fasting. However, meals decreased rectal compliance significantly in diarrhea predominant IBS patients, while constipation predominant IBS patients did not show a postprandial hypo-compliance. ${ }^{114}$ Meal-induced rectal hypocompliance was also found to be sig- 
nificantly correlated with increased bowel movements. ${ }^{114}$ Therefore, changes in compliance after meal ingestion depended on the subgroup of IBS, but these were insignificant during fasting state. The complaints in some IBS patients of stool passage right after meal ingestion may stem from rectal hypocompliance after meals.

Recently, rectal accommodation, defined as the volume change of a barostat bag during distension, was reported to be the same for both IBS patients and normal controls. However, subgroup analysis in the study revealed significantly lower rectal accommodation in diarrhea predominant IBS patients than in normal controls. ${ }^{115}$ Also, rectal accommodation tended to be associated with the severity of abdominal pain during rectal distension. Abnormal rectal physiology is therefore important in producing IBS symptoms. ${ }^{115}$

\section{Gallbladder}

Altered gallbladder motor patterns have been found in some IBS patients. Abnormal gallbladder motility arises from the response to specific stimuli such as foods and stress in IBS patients. One Japanese group investigated gallbladder motor function after caerulein injection in IBS patients. ${ }^{116}$ They measured gallbladder area before and after caerulein injection and calculated gallbladder contraction rates. Constipation predominant IBS patients were shown to have hyperkinetic rates, whereas the diarrhea predominant group tended towards hypokinetic rates. Unfortunately, there have been only a few studies of gallbladder motility of IBS.

\section{Conclusion}

Although many studies have shown that IBS patients have various GI motor disturbances, these altered motilities are neither specific nor diagnostic for IBS. Altered motility can be primary or secondary, and it is not always correlated with IBS symptoms. Therefore, a causal relationship between GI motility changes and IBS symptoms remains controversial. However, it is undoubtedly true that altered motility is one of the major pathophysiologic factors of IBS. Multinational, multicenter studies are needed to clarify the differences in GI motor function between Asian and Western populations.

\section{References}

1. Bradette M, Delvaux M, Staumont G, Fioramonti J, Bueno L, Frexinos J. Evaluation of colonic sensory thresholds in IBS patients using a barostat: definition of optimal conditions and comparison with healthy subjects. Dig Dis Sci 1994;39:449-457.

2. Kellow JE, Eckersley GM, Jones MP. Enhanced perception of physiological intestinal motility in the irritable bowel syndrome. Gastroenterology 1991;101:1621-1627.

3. Mertz H, Naliboff B, Munakata J, Niazi N, Mayer EA. Altered rectal perception is a biological marker of patients with irritable bowel syndrome. Gastroenterology 1995;109:40-52.

4. Naliboff BD, Munakata J, Fullerton S, et al. Evidence for two distinct perceptual alterations in irritable bowel syndrome. Gut 1997;41:505-512.

5. Prior A, Sorial E, Sun WM, Read NW. Irritable bowel syndrome: differences between patients who show rectal sensitivity and those who do not. Eur J Gastroenterol Hepatol 1993;5:343-349.

6. Ritchie J. Pain from distension of the pelvic colon by inflating a balloon in the irritable colon syndrome. Gut 1973;14:125-132.

7. Sun WM, Read NW, Prior A, Daly JA, Cheah SK, Grundy D. Sensory and motor responses to rectal distention vary according to rate and pattern of balloon inflation. Gastroenterology 1990;99: 1008-1015.

8. Whitehead WE, Palsson OS. Is rectal pain sensitivity a biological marker for irritable bowel syndrome: psychological influences on pain perception. Gastroenterology 1998;115:1263-1271.

9. Dickhaus B, Mayer EA, Firooz N, et al. Irritable bowel syndrome patients show enhanced modulation of visceral perception by auditory stress. Am J Gastroenterol 2003;98:135-143.

10. Murray CD, Flynn J, Ratcliffe L, Jacyna MR, Kamm MA, Emmanuel AV. Effect of acute physical and psychological stress on gut autonomic innervation in irritable bowel syndrome. Gastroenterology 2004;127:1695-1703.

11. Posserud I, Agerforz P, Ekman R, Björnsson ES, Abrahamsson H, Simrén M. Altered visceral perceptual and neuroendocrine response in patients with irritable bowel syndrome during mental stress. Gut 2004;53:1102-1108.

12. Rogers J, Henry MM, Misiewicz JJ. Increased segmental activity and intraluminal pressures in the sigmoid colon of patients with the irritable bowel syndrome. Gut 1989;30:634-641.

13. Corbett CL, Thomas S, Read NW, Hobson N, Bergman I, Holdsworth CD. Electrochemical detector for breath hydrogen determination: measurement of small bowel transit time in normal subjects and patients with the irritable bowel syndrome. Gut 1981;22:836-840.

14. Lu WZ, Song GH, Gwee KA, Ho KY. The effects of melatonin on colonic transit time in normal controls and IBS patients. Dig Dis Sci 2009;54:1087-1093.

15. Spiller R, Aziz Q, Creed F, et al. Guidelines on the irritable bowel syndrome: mechanisms and practical management. Gut 2007;56: 1770-1798.

16. Drossman DA, Camilleri M, Mayer EA, Whitehead WE. AGA technical review on irritable bowel syndrome. Gastroenterology 
2002;123:2108-2131.

17. Lu CL, Chen CY, Chang FY, et al. Effect of a calcium channel blocker and antispasmodic in diarrhoea-predominant irritable bowel syndrome. J Gastroenterol Hepatol 2000;15:925-930.

18. Lee SY, Lee KJ, Kim SJ, Cho SW. Prevalence and risk factors for overlaps between gastroesophageal reflux disease, dyspepsia, and irritable bowel syndrome: a population-based study. Digestion 2009;79:196-201.

19. Whorwell PJ, Clouter C, Smith CL. Oesophageal motility in the irritable bowel syndrome. Br Med J (Clin Res Ed) 1981;282: 1101-1102.

20. Soffer EE, Scalabrini P, Pope CE 2nd, Wingate DL. Effect of stress on oesophageal motor function in normal subjects and in patients with the irritable bowel syndrome. Gut 1988;29:1591-1594.

21. Lind CD. Motility disorders in the irritable bowel syndrome. Gastroenterol Clin North Am 1991;20:279-295.

22. Roshandel D, Rezailashkajani M, Shafaee S, Zali MR. Symptom patterns and relative distribution of functional bowel disorders in 1,023 gastroenterology patients in Iran. Int $\mathrm{J}$ Colorectal Dis 2006;21:814-825.

23. Masud MA, Hasan M, Azad Khan AK. Irritable bowel syndrome in a rural community in Bangladesh: prevalence, symptoms pattern, and health care seeking behavior. Am J Gastroenterol 2001;96: 1547-1552.

24. Si JM, Wang LJ, Chen SJ, Sun LM, Dai N. Irritable bowel syndrome consulters in Zhejiang province: the symptoms pattern, predominant bowel habit subgroups and quality of life. World J Gastroenterol 2004;10:1059-1064.

25. Shiotani A, Miyanishi T, Takahashi T. Sex differences in irritable bowel syndrome in Japanese university students. J Gastroenterol 2006;41:562-568.

26. Hu WH, Wong WM, Lam CL, et al. Anxiety but not depression determines health care-seeking behaviour in Chinese patients with dyspepsia and irritable bowel syndrome: a population-based study. Aliment Pharmacol Ther 2002;16:2081-2088.

27. Shah SS, Bhatia SJ, Mistry FP. Epidemiology of dyspepsia in the general population in Mumbai. Indian J Gastroenterol 2001;20: 103-106.

28. Lu CL, Lang HC, Chang FY, et al. Prevalence and health/social impacts of functional dyspepsia in Taiwan: a study based on the Rome criteria questionnaire survey assisted by endoscopic exclusion among a physical check-up population. Scand J Gastroenterol 2005;40:402-411.

29. Wang A, Liao X, Xiong L, et al. The clinical overlap between functional dyspepsia and irritable bowel syndrome based on Rome III criteria. BMC Gastroenterol 2008;8:43.

30. Chen MH, Zhong BB, Li CJ. An epidemiologic study of dyspepsia in Guangdong area. J Gastroenterol Hepatol 1997;12:A199.

31. Fava GA, Pavan L. Large bowel disorders. I. Illness configuration and life events. Psychother Psychosom 1976;27:93-99.

32. Mendeloff AI, Monk M, Siegel CI, Lilienfeld A. Illness experience and life stresses in patients with irritable colon and with ulcerative colitis. An epidemiologic study of ulcerative colitis and regional enteritis in Baltimore, 1960-1964. N Engl J Med 1970;282:14-17.

33. Whitehead WE, Crowell MD, Robinson JC, Heller BR, Schuster MM. Effects of stressful life events on bowel symptoms: subjects with irritable bowel syndrome compared with subjects without bowel dysfunction. Gut 1992;33:825-830.

34. Badiali D, Pallota N, Habib FI, et al. Gastric emptying is delayed in slow colonic transit constipation [abstract]. Gastroenterology 1998; 114:G2958.

35. Coremans G, Wilmer A, Andrioli A, et al. Slow transit constipation is associated with delayed gastric emptying and impaired small bowel motility [abstract]. Neurogastroenterol Motil 1995;7:252.

36. Stanghellini V, Tosetti C, Barbara G, et al. Dyspeptic symptoms and gastric emptying in the irritable bowel syndrome. Am J Gastroenterol 2002;97:2738-2743.

37. Nielsen OH, Gjorup T, Christensen FN. Gastric emptying rate and small bowel transit time in patients with irritable bowel syndrome determined with $99 \mathrm{mTc}$-labeled pellets and scintigraphy. Dig Dis Sci 1986;31:1287-1291.

38. Narducci F, Bassotti G, Granata MT. Colonic motility and gastric emptying in patients with irritable bowel syndrome. Effect of pretreatment with octylonium bromide. Dig Dis Sci 1986;31:241-246.

39. Acharya U, Waite N, Howlett P, Tanner AR, Smith CL. Failure to demonstrate altered gastric emptying in irritable bowel syndrome. Dig Dis Sci 1983;28:889-892.

40. Evans PR, Bak YT, Shuter B, Hoschl R, Kellow JE. Gastroparesis and small bowel dysmotility in irritable bowel syndrome. Dig Dis Sci 1997;42:2087-2093.

41. Seo JC, Lee KS, Jeon WJ, et al. Gastric emptying time and electrogastrographic studies in patient with irritable bowel syndrome. Korean J Gastroenterol 2000;35:319-325.

42. Welgan P, Meshkinpour H, Ma L. Role of anger in antral motor activity in irritable bowel syndrome. Dig Dis Sci 2000;45:248-251.

43. Cann PA, Read NW, Brown C. Irritable bowel syndrome: relationship of disorders in the transit of a single solid meal to symptom patterns. Gut 1983;24:405-411.

44. Lu CL, Chen CY, Chang FY, Lee SD. Characteristics of small bowel motility in patients with irritable bowel syndrome and normal humans: an Oriental study. Clin Sci (Lond) 1998;95:165-169.

45. Kellow JE, Gill RC, Wingate DL. Prolonged ambulant recordings of small bowel motility demonstrate abnormalities in the irritable bowel syndrome. Gastroenterology 1990;98:1208-1218.

46. Kellow JE, Phillips SF, Miller LJ, Zinsmeister AR. Dysmotility of the small intestine in irritable bowel syndrome. Gut 1988;29: 1236-1243.

47. Kellow JE, Phillips SF. Altered small bowel motility in irritable bowel syndrome is correlated with symptoms. Gastroenterology 1987;92:1885-1893.

48. Quigley EM. Intestinal manometry - technical advances, clinical limitations. Dig Dis Sci 1992;37:10-13.

49. Quigley EM, Donovan JP, Lane MJ, Gallagher TF. Antroduodenal manometry. Usefulness and limitations as an outpatient study. Digestive Diseases and Sciences 1992;37:20-28.

50. Summers RW, Anuras S, Green J. Jejunal manometry patterns in health, partial intestinal obstruction, and pseudoobstruction. Gastroenterology 1983;85:1290-1300.

51. Stanghellini V, Camilleri M, Malagelada JR. Chronic idiopathic intestinal pseudo-obstruction: clinical and intestinal manometric findings. Gut 1987;28:5-12.

52. Hackelsberger N, Schmidt T, Renner R. Ambulatory long-term je- 
junal manometry in diabetic patients with cardiac autonomic neuropathy. Neurogastroenterol motil 1997;9:77-83.

53. Wang SH, Dong L, Luo JY, et al. A research of migrating motor complex in patients with irritable bowel syndrome. Zhonghua Nei Ke Za Zhi 2009;48:106-110.

54. Gorard DA, Libby GW, Farthing MJ. Ambulatory small intestinal motility in 'diarrhoea' predominant irritable bowel syndrome. Gut 1994;35:203-210.

55. Kumar D, Wingate DL. The irritable bowel syndrome: A proxysmal disorder. Lancet 1985;2:973-977.

56. Zhao JH, Dong L, Hao XQ. Small intestine motility and gastrointestinal hormone levels in irritable bowel syndrome. Nan Fang Yi Ke Da Xue Xue Bao 2007;27:1492-1495.

57. Thompson DG, Wingate DL, Archer L, Benson MJ, Green WJ, Hardy RJ. Normal patterns of human upper small bowel motor activity recorded by prolonged radiotelemetry. Gut 1980;21:500-506.

58. Kellow JE, Langeluddecke PM, Eckersley GM, Jones MP, Tennant CC. Effects of acute psychologic stress on small-intestinal motility in health and the irritable bowel syndrome. Scand J Gastroenterol 1992;27:53-58.

59. Fukudo S, Nomura T, Hongo M. Impact of corticotropin-releasing hormone on gastrointestinal motility and adrenocorticotropic hormone in normal controls and patients with irritable bowel syndrome. Gut 1998;42:845-849.

60. Ke MY, Li RQ, Pan GZ. Gastrointestinal transit time (GITT) in normal Chinese and patients. Zhonghua Nei Ke Za Zhi 1990; 29:723-726,765.

61. Konturek SJ, Konturek PC, Brzozowska I, et al. Localization and biological activities of melatonin in intact and diseased gastrointestinal tract (GIT). J Physiol Pharmacol 2007;58:381-405.

62. Thor PJ, Krolczyk G, Gil K, Zurowski D, Nowak L. Melatonin and serotonin effects on gastrointestinal motility. J Physiol Pharmacol 2007;58(suppl 6):97-103.

63. Agarwal MK, Bhatia SJ, Desai SA, Bhure U, Melgiri S. Effect of red chillies on small bowel and colonic transit and rectal sensitivity in men with irritable bowel syndrome. Indian J Gastroenterol 2002; 21:179-182.

64. Horikawa Y, Mieno H, Inoue M, Kajiyama G. Gastrointestinal motility in patients with irritable bowel syndrome studied by using radiopaque markers. Scand J Gastroenterol 1999;34:1190-1195.

65. Ghoshal UC, Abraham P, Bhatt C, et al. Epidemiological and clinical profile of irritable bowel syndrome in India: report of the Indian Society of Gastroenterology Task Force. Indian J Gastroenterol 2008;27:22-28.

66. Danivat D, Tankeyoon M, Sriratanaban A. Prevalence of irritable bowel syndrome in a non-Western population. Br Med J (Clin Res Ed) $1988 ; 296: 1710$.

67. Kwan AC, Hu WH, Chan YK, Yeung YW, Lai TS, Yuen H. Prevalence of irritable bowel syndrome in Hong Kong. J Gastroenterol Hepatol 2002;17:1180-1186.

68. Kim YJ, Ban DJ. Prevalence of irritable bowel syndrome, influence of lifestyle factors and bowel habits in Korean college students. Int J Nurs Stud 2005;42:247-254.

69. Fang X, Lu S, Pan G. An epidemiologic study of bowel habit in adult non-patient population in Beijing area. Zhonghua Yi Xue Za Zhi 2001;81:1287-1290.
70. Ghoshal UC, Gupta D, Kumar A, Misra A. Colonic transit study by radio-opaque markers to investigate constipation: validation of a new protocol for a population with rapid gut transit. Natl Med J India 2007;20:225-229.

71. Singh N, Makharia GK, Joshi YK. Dietary survey and total dietary fiber intake in patients with irritable bowel syndrome attending a tertiary referral hospital. Indian J Gastroenterol 2008;27:66-70.

72. Tandon RK, Prasad N, Gupta MC, Tandon BN. Stool weights and transit time in North Indians. J Assoc Physicians India 1976; 24:807-810.

73. Bouchoucha M, Devroede G, Arhan P, et al. What is the meaning of colorectal transit time measurement? Dis Colon Rectum 1992;35: 773-782.

74. Koo C, Kim MJ, Sung JH, et al. Colonic transit time in irritable bowel syndrome. Korean J Med 1991;41:324-331.

75. Chan YK, Kwan AC, Yuen H, et al. Normal colon transit time in healthy Chinese adults in Hong Kong. J Gastroenterol Hepatol 2004;19:1270-1275.

76. Nar YH, Lyou JH, You KH, Choi SC. Differential diagnosis of the irritable bowel syndrome - diagnostic value of the colorectal physiology test in the exclusion of organic disease. Korean J Med 1996;51:194-200.

77. Vassallo M, Camilleri M, Phillips SF, Brown ML, Chapman NJ, Thomforde GM. Transit through the proximal colon influences stool weight in the irritable bowel syndrome. Gastroenterology 1992;102:102-108.

78. Chiba T, Kudara N, Sato M, et al. Colonic transit, bowel movements, stool form, and abdominal pain in irritable bowel syndrome by treatments with calcium polycarbophil. Hepatogastroenterology 2005;52:1416-1420.

79. Zhang WQ, Yan GZ, Yu LZ, Yang XQ. Non-invasive measurement of pan-colonic pressure over a whole digestive cycle: clinical applications of a capsule-style manometric system. World J Gastroenterol 2006;12:7690-7694.

80. Vassallo MJ, Camilleri M, Phillips SF, et al. Colonic tone and motility in patients with irritable bowel syndrome. Mayo Clinic Proceedings 1992;67:725-731.

81. Chey WY, Jin HO, Lee MH, Sun SW, Lee KY. Colonic motility abnormality in patients with irritable bowel syndrome exhibiting abdominal pain and diarrhea. Am J Gastroenterol 2001;96:14991506.

82. Dinan TG, O'Keane V, O'Boyle C, Chua A, Keeling PW. A comparison of the mental status, personality profiles and life events of patients with irritable bowel syndrome and peptic ulcer disease. Acta Psychiatr Scand 1991;84:26-28.

83. Levy RL, Cain KC, Jarrett M, Heitkemper MM. The relationship between daily life stress and gastrointestinal symptoms in women with irritable bowel syndrome. J Behav Med 1997;20:177-193.

84. Walker LS, Garber J, Smith CA, Van Slyke DA, Claar RL. The relation of daily stressors to somatic and emotional symptoms in children with and without recurrent abdominal pain. J Consult Clin Psychol 2001;69:85-91.

85. Kanazawa M, Endo Y, Whitehead WE, Kano M, Hongo M, Fukudo S. Patients and nonconsulters with irritable bowel syndrome reporting a parental history of bowel problems have more impaired psychological distress. Dig Dis Sci 2004;49:1046-1053. 
86. Chakraborti SK, Dey BK, Ghosh N, Chaudhury AN, Guha Mazumder DN. Objective evaluation of psychological abnormality in irritable bowel syndrome. Indian J Gastroenterol 1996;15:43-45.

87. Han SH, Lee OY, Lee YS, Kim KB, Yoon BC, Choi HS. Anxiety, depression and sleep disturbance in female constipation predominant irritable bowel syndrome. Korean J Gastrointest Motil 2005;11:66-71

88. Cho KR, Lee OY, Yoon DH, et al. The influence of depression on gastrointestinal symptoms in women. Korean J Gastrointest Motil 2007;13:146-151.

89. Endo Y. Panic disorder in irritable bowel syndrome. Jpn J psychosom Med 2000;40:339-346.

90. Creed F, Craig T, Farmer R. Functional abdominal pain, psychiatric illness, and life events. Gut 1988;29:235-242.

91. Drossman DA, Li Z, Leserman J, Toomey TC, Hu YJ. Health status by gastrointestinal diagnosis and abuse history. Gastroenterology 1996;110:999-1007.

92. Fukudo S, Hongo M. Irritable bowel syndrome: a disorder of abnormal brain-gut interactions. Jpn J psychosom Med 1999;39: 159-166.

93. Shinozaki M, Fukudo S, Hongo M, et al. High prevalence of irritable bowel syndrome in medical outpatients in Japan. J Clin Gastroenterol 2008;42:1010-1016

94. Welgan P, Meshkinpour H, Beeler M. Effect of anger on colon motor and myoelectric activity in irritable bowel syndrome. Gastroenterology 1988;94:1150-1156.

95. Fukudo S, Suzuki J. Colonic motility, autonomic function, and gastrointestinal hormones under psychological stress on irritable bowel syndrome. Tohoku J Exp Med 1987;151:373-385.

96. Taché Y, Martinez V, Million M, Maillot C. Role of corticotropin releasing factor subtype 1 in stress-related functional colonic alterations: implications in irritable bowel syndrome. Eur J Surg Suppl 2002;587:16-22.

97. Barquist E, Zinner M, Rivier J, Taché Y. Abdominal surgery-induced delayed gastric emptying in rats: role of CRF and sensory neurons. Am J Physiol 1992;262:G616-620.

98. Monnikes H, Schmidt BG, Tache Y. Psychological stress-induced accelerated colonic transit in rats involves hypothalamic corticotropin-releasing factor. Gastroenterology 1993;104:716-723.

99. Gue M, Junien JL, Bueno L. Conditioned emotional response in rats enhances colonic motility through the central release of corticotropin-releasing factor. Gastroenterology 1991;100:964-970.

100. Sagami Y, Shimada Y, Tayama J, et al. Effect of a corticotropin releasing hormone receptor antagonist on colonic sensory and motor function in patients with irritable bowel syndrome. Gut 2004;53: 958-964.

101. Maillot C, Million M, Wei JY, Gauthier A, Tache Y. Peripheral corticotropin-releasing factor and stress-stimulated colonic motor activity involve type 1 receptor in rats. Gastroenterology 2000;119: 1569-1579.
102. Mancinelli R, Azzena GB, Diana M, Forgione A, Fratta W. In vitro excitatory actions of corticotropin-releasing factor on rat colonic motility. J Auton Pharmacol 1998;18:319-324.

103. Fukudo S, Kanazawa M, Kano M, et al. Exaggerated motility of the descending colon with repetitive distention of the sigmoid colon in patients with irritable bowel syndrome. J Gastroenterol 2002;37: $145-150$

104. Kusunoki H, Kamada T, Sato M, Haruma K, Hata J. Ultrasonographic assessment of sigmoid colon in patients with irritable bowel syndrome. Nippon Rinsho 2006;64:1461-1466.

105. Jeong JB, Yang YM, Jeon WJ, et al. Postprandial colonic motor activity in patients with irritable bowel syndrome. Korean J Gastrointest Motil 2000;6:20-30.

106. Shah SK, Abraham P, Mistry FP. Effect of cold pressor test and a high-chilli diet on rectosigmoid motility in irritable bowel syndrome. Indian J Gastroenterol 2000;19:161-164.

107. Gonlachanvit S, Mahayosnond A, Kullavanijaya P. Effects of chili on postprandial gastrointestinal symptoms in diarrhoea predominant irritable bowel syndrome: evidence for capsaicin-sensitive visceral nociception hypersensitivity. Neurogastroenterol Motil 2009; 21:23-32.

108. Lee KJ, Sin SS, Kim JH, Hahm KB, Cho SW. Differences of anorectal manometry between diarrhea- and constipation-predominant irritable bowel syndrome. Korean J Gastroenterol 2000;36:483492.

109. Prior A, Maxton DG, Whorwell PJ. Anorectal manometry in irritable bowel syndrome: differences between diarrhoea and constipation predominant subjects. Gut 1990;31:458-462.

110. Park JH, Baek YH, Park DI, et al. Analysis of rectal dynamic and static compliances in patients with irritable bowel syndrome. Int $\mathrm{J}$ Colorectal Dis 2008;23:659-664.

111. Distrutti E, Salvioli B, Azpiroz F, Malagelada JR. Rectal function and bowel habit in irritable bowel syndrome. Am J Gastroenterol 2004;99:131-137.

112. Whitehead WE, Engel BT, Schuster MM. Irritable bowel syndrome. Physiological and psychological differences between diarrhea-predominant and constipation-predominant patients. Dig Dis Sci 1980;25:404-413.

113. Ragnarsson G, Hallbook O, Bodemar G. Abdominal symptoms and anorectal function in health and irritable bowel syndrome. Scand J Gastroenterol 2001;36:833-842.

114. Lee KJ, Kim JH, Cho SW. Relationship of underlying abnormalities in rectal sensitivity and compliance to distension with symptoms in irritable bowel syndrome. Digestion 2006;73:133-141.

115. Moon W, Lee OY, Kim JM, et al. Rectal accommodation in irritable bowel syndrome. Korean J Gastrointest Motil 2007;13: 132-137.

116. Kanazawa F, Mine K, Mishima N, Muraoka M, Nakagawa T. A study of the dynamics of gallbladder contraction in irritable bowel syndrome. Nippon Shokakibyo Gakkai Zasshi 1992;89:1185- 1190. 